\title{
Olive Oil Extract/Curcumin-based Capsule
}

National Cancer Institute

\section{Source}

National Cancer Institute. Olive Oil Extract/Curcumin-based Capsule. NCI Thesaurus. Code C106234.

A capsule containing an extract of olive oil, rich in polyphenols, and curcumin, the polyphenol derived from the plant Curcuma longa, also known as turmeric, with potential anti-neoplastic, -angiogenic, -inflammatory, -oxidant and chemopreventive activities. The olive oil extract/curcumin-based capsule is rich in phytonutrients, especially polyphenols. Upon oral administration, the polyphenols, and other active ing redients in this supplement may exert anti-inflammatory activity by decreasing the production of inflammation mediators, such as TNF-alpha, interleukin (IL) 1-beta, IL-6, IL-10, interferon gamma, thromboxane B2, and leukotriene B4. They also inhibit a variety of pro-inflammatory enzymes, such as cyclooxygenase 1 (COX-1) and COX-2, block the formation of reactiveoxygen species and neutralize free radicals. In addition, curcumin and some other polyphenols disrupt cell signal transduction pathways involved in carcinogenesis. Specifically, curcumin inhibits cell invasion by inhibiting matrix metalloproteinase-9 (MMP9) expression by suppressing NF-kB and AP-1 activation. 